\title{
Association of cytokines with endothelium dependent flow mediated vasodilation (FMD) of systemic arteries in patients with non-ischemic cardiomyopathy
} Katja B Vallbracht-Israng*1, Ilkay Kazak ${ }^{2}$ and Peter L Schwimmbeck ${ }^{3}$

Address: 'Department of Cardiology, Campus Virchow Hospital, Charité Medical University, Augustenburger Platz 1, 13353 Berlin, Germany, ${ }^{2}$ Department of ENT, Campus Benjamin Franklin, Charité Medical University, Hindenburgdamm 30, 12200 Berlin, Germany and ${ }^{3}$ Department of Cardiology, Hospital Leverkusen, Am Gesundheitspark 11, 51375 Leverkusen, Germany

Email: Katja B Vallbracht-Israng* - katja.vallbracht-israng@charite.de; Ilkay Kazak - ilkay.kazak@charite.de; Peter L Schwimmbeck - peter.schwimmbeck@charite.de

* Corresponding author

Published: 10 December 2007

Cardiovascular Ultrasound 2007, 5:49 doi:1 0.1 | 86/| 476-7| 20-5-49
Received: 25 October 2007

Accepted: 10 December 2007

This article is available from: http://www.cardiovascularultrasound.com/content/5/I/49

(c) 2007 Vallbracht-Israng et al; licensee BioMed Central Ltd.

This is an Open Access article distributed under the terms of the Creative Commons Attribution License (http://creativecommons.org/licenses/by/2.0), which permits unrestricted use, distribution, and reproduction in any medium, provided the original work is properly cited.

\begin{abstract}
Background: Aim of this study was to elucidate the relation between localised inflammatory heart disease and endothelial dysfunction in the peripheral circulation, considering circulating cytokines as a potential link.
\end{abstract}

Methods: In 38 patients with non-ischemic heart disease, myocardial biopsies were examined for myocardial inflammation (immunohistology) and virus persistence (PCR). Cytokines (sIL-4, IFN-g, IFN-b, IFN-a, sIL-12p7, TNF-a) were measured by ELISA in venous serum. Endothelial function of the radial artery was examined by ultrasound, measuring diameter changes in response to reactive hyperemia (FMD), compared to glyceroltrinitrate (GTN-MD). Patients with EF < 35\% were excluded.

Results: Age $44 \pm 14$ years, 19 male, 19 female, EF 63.5[16]\%. FMD 4.38 [4.82]\%. 30 patients had myocardial inflammation (8 not), 23 virus persistence ( 15 not). FMD correlated significantly with sIL-12p7 ( $p=0.024, r=-0.365$ ), but not with other cytokines. sIL- $12 p 7$ levels were significantly higher in patients with severely impaired FMD $(n=17)$, compared with normal FMD $(n=21)$ : 10.70 $[10.72]$ vs. $4.33[7.8 \mathrm{I}] \mathrm{pg} / \mathrm{ml}(\mathrm{p}=0.002)$. Endothelium independent vasodilation (GTN-MD 23.67 $[8.21] \%)$ was not impaired.

Conclusion: Endothelial dysfunction of peripheral arteries in patients with non-ischemic cardiomyopathy is associated with elevated serum concentrations of sIL-12p7, but not of other cytokines. Circulating sIL-12p7 may partly explain, that endothelial dysfunction is not restricted to the coronary circulation, but involves systemic arteries.

\section{Background}

Endothelial dysfunction in patients with non-ischemic heart disease, which has been observed in the coronary circulation [1] as well as in systemic arteries [2,3], is asso- ciated with myocardial inflammatory immune responses. Other groups have demonstrated endothelial dysfunction in systemic infections, like after thyphoid vaccination [4], Kawasaki disease [5], in systemic vasculitis [6] and in 
association with elevated CRP-levels [7]. In the Framingham Offspring Study with 2701 patients, an association between systemic inflammation and endothelial dysfunction was confirmed [8]. Endothelial dysfunction may determine prognosis, as has been demonstrated for patients with atherosclerosis [9-11] and after transplantation [12]. Non-invasive measurement of endothelial dysfunction is preferred to invasive measurements. However, the link between peripheral endothelial dysfunction and non-ischemic heart disease, needs to be determined. Inflammatory parameters have been associated with an increased risk of cardiovascular events $[13,14]$ or the progression of heart failure [15], similar to the observations for endothelial function. Therefore, we consider circulating cytokines a potential link between non-ischemic heart disease and peripheral endothelial dysfunction. Heart failure itself is associated with endothelial dysfunction [16-19] as well as with changes in the pattern of circulating cytokines [20,21], however endothelial dysfunction of peripheral arteries is also observed in patients with nonischemic heart disease and only mildly or regionally impaired left ventricular function. The aim of this study was to elucidate the relation between non-ischemic heart disease (in the absence of heart failure) and endothelial dysfunction in the peripheral circulation, considering circulating cytokines potential candidates for a link.

\section{Methods}

We included 38 patients with non-ischemic heart disease, considering history, physical examination and non-invasive tests, that were referred to our hospital for acquisition and examination of myocardial biopsies. Inclusion criteria were 1 . suspected cardiomyopathy by history and symptoms (chest pain, dyspnea, palpitations, exercise intolerance) or by history and ECG-changes (ST-/T-deviations, rhythm disturbances) and 2. echocardiographic regional wall motion abnormalities or global left ventricular dysfunction. Duration of symptoms was at least 3 months. By left ventricular catheterization and angiography, coronary artery disease was excluded, left ventricular ejection fraction and pressures were measured. Right-ventricular catheterization was performed to obtain endomyocardial biopsies and perform hemodynamic measurements. To minimize other confounding factors on endothelial dysfunction, patients with coronary artery disease [9-11], diabetes [22], more than one other risk factor for arteriosclerosis [22-24], overt arteriosclerosis or other severe disease were excluded from this study. As heart failure is known to affect endothelial function [1619] as well as cytokine levels [20,21], we excluded patients with an ejection fraction $<35 \%$. At the time of the study, the majority of patients was already on cardiovascular medication [19], which was ceased according to half-life prior to the study, though this may not be necessary [25].
Sinus rhythm was required. The patients did not receive any immunomodulatory therapies.

Informed consent was obtained from all patients.

\section{Endothelial function}

Endothelial function of the radial artery was measured, as published previously $[2,3]$. By high resolution ultrasound, diameter changes in response to reactive hyperemia (FMD), compared to glyceroltrinitrate (GTN-MD), were detected, referring to the standard protocols [26-28]. Flow mediated vasodilation in response to reactive hyperemia (FMD) represents endothelium dependent vasoreactivity, whereas vasodilation in response to glyceroltrinitrate (GTN-MD) indicates endothelium independent smooth muscle cell function.

\section{Calculations}

FMD represents the percentage of diameter increase caused by shear stress, compared to baseline. GTN-MD represents the percentage of diameter increase induced by GTN, compared to baseline.

\section{Cytokine measurements}

Venous blood samples were obtained from the cubital vein from each patient by standard venous puncture. Samples were immediately centrifuged and the serum stored at $-80^{\circ} \mathrm{C}$. Cytokine measurements (sIL-4, IFN-g, IFN-b, IFN$\mathrm{a}$, sIL-12p7 and TNF-a) were performed with standard sandwich enzyme immunoassay (ELISA) kits according to the manufacturer's instructions: Hölzel Diagnostica Handels GmbH Pelikine Compact TM human IFN ELISA kits (sensitivity $1 \mathrm{pg} / \mathrm{ml}$ ), Hölzel Diagnostica Handels GmbH Pelikine Compact TM human IL-4 ELISA kit (sensitivity $0.2 \mathrm{pg} / \mathrm{ml}$ ), Genzyme Diagnostics PredictaHuman Total Interleukin 12 ELISA kit (sensitivity $10 \mathrm{pg} / \mathrm{ml}$ ).

\section{Myocardial biopsies}

Endomyocardial biopsies from the right ventricular septum were obtained by standard percutaneous transvenous femoral approach with a standard bioptome.

\section{Immunohistology}

For immunohistological evaluation, the samples were prepared and evaluated as published previously [1$3,29,30]$. Immunohistologically stained leucocytes (CD2+, CD3+, CD4+, CD8+ and activated CD45RO+ lymphocytes, macrophages) were counted per high-power field (400-fold magnification, equivalent to $0.28 \mathrm{~mm}^{2}$ ). Endothelial expression of HLA-1, HLA-DR and ICAM-1 was scaled $(1,2,3)$, according to intensity of immunoperoxidase staining. Myocardial inflammation was confirmed in myocardial biopsies, if more than 7 CD3+ lymphocytes per $1 \mathrm{~mm}^{2}$ tissue were identified and/or if endothelial expression of cell adhesion molecules was 
enhanced. Myocardial biopsies were examined and analyzed by two independent blinded observers.

\section{Statistical analysis}

Statistical analysis was performed with the SPSS Inc. (Chicago, Illinois) software, version 12.0 for IBM-PC. Descriptive data are expressed as median and interquartile range. Quantitative data were compared to qualitative data by use of the Kruskal-Wallis test on rank sums for independent samples, followed by a post hoc multiple comparison procedure, if appropriate. To compare quantitative data of two groups, the Mann Whitney U test was applied. Quantitative data were correlated by use of the Spearman $p$ rank-order analysis, calculating the coefficient of correlation $\mathrm{r}$. Statistical significance was inferred at $\mathrm{p}<0.05$.

\section{Results \\ Patients characteristics}

General characteristics

Mean age of the 38 patients was 44.5518 years, 19 were male, 19 female. At the time of investigation, all patients were normotensive ( 9 treated for hypertension) and had normal lipid-levels (8 treated with statins), 4 were smokers. Of the patients on standard cardiovascular medication, 11 were treated with ACE-inhibitors, 1 with AT1antagonists, 9 with betablockers, 2 with calciumantagonists and 5 with digitalis glucosides.

\section{Clinical presentation and history}

29 patients presented with chest pain (angina), 12 with palpitations, 34 with fatigue or exercise intolerance. At the time of inclusion in the study, all patients were in NYHAstage I-II.

\section{Non-invasive examinations}

ST-segment or T-wave changes were documented in the ECGs of 11 patients, rhythm disturbances in 9 patients. Echocardiography revealed regional wall motion abnormalities or an impaired global systolic left ventricular function, according to the inclusion criteria. Pericardial effusions were not observed.

\section{Hemodynamic measurements}

Left ventricular ejection fraction (EF) was 63.5[16]\%, left ventricular enddiastolic pressure (LVEDP) $74 \mathrm{mmHg}$, pulmonary capillary wedge pressure (PCWP) $66 \mathrm{mmHg}$; cardiac output (CO) $5.652 \mathrm{l} / \mathrm{min}$ and cardiac index (CI) 31 $\left(1 / \mathrm{min} / \mathrm{m}^{2}\right)$.

\section{Myocardial biopsies}

Myocardial inflammation or endothelial activation was confirmed by immunohistology in myocardial biopsies in $30 / 38$ patients, according to the criteria described above. In $8 / 38$ patients no inflammatory immune response was detected. In 23/38 patients, myocardial virus persistence was demonstrated in myocardial biopsies, 15/38 had no myocardial virus persistence. Endothelial activation (sumscore) was 64, leukocyte counts were 0.8 [1.2] CD2+, 0.8 [1.1] CD3+, 0.3 [0.5] CD4+, 0.3 [0.4] CD8+, 0.8 [1.3] CD45RO and 0.95 [1.2] macrophages. Myocyte necrosis were not observed in this study population.

\section{Cytokine measurements}

Serum concentration for sIL-4 was 37.65 [39.57], for IFNg 4.75 [4.5], for IFN-b 34.90 [25.4], for IFN-a 1.55 [1.57], for sIL-12p7 8.31 [9.64] and for TNF-a 7.09 [11.67] pg/ $\mathrm{ml}$.

Serum concentrations of TNFa correlated significantly with myocardial CD3+ lymphocytes $(\mathrm{r}=-0.382, \mathrm{p}=$ 0.020 ), no correlations were observed between TNFa and other myocardial leukocytes or other cytokines and myocardial leukocytes. No correlation was observed between cytokine concentrations and endothelial activation. Concentrations of IFNg correlated significantly with PCWP (p $=0.001, \mathrm{r}=0.571)$, no correlations were observed between the other cytokines and hemodynamic parameters. Concentrations of IFNb and IFNa were inversely correlated ( $\mathrm{p}=0.041, \mathrm{r}=-0.333)$, no correlations were observed between the other cytokines.

CRP-levels were below $6 \mathrm{mg} / \mathrm{l}$ and white cell counts were normal in the study population.

\section{Endothelial function}

General Characteristics

Heart rate and blood-pressure (systolic and diastolic) did not change significantly during measurements with reactive hyperemia and after application of glyceroltrinitrate. Adequate reactive hyperemia was achieved in all subjects. Mean resting diameter of the radial artery was $2.34[1] \mathrm{mm}$ at baseline, after reactive hyperemia the mean diameter increased to $2.52[1] \mathrm{mm}$ and after glyceroltrinitrate (GTN) to $2.93[1] \mathrm{mm}$.

\section{Flow mediated vasodilation}

Endothelial function, as determined by FMD of the radial artery, was impaired in the study population (FMD 4.38 [4.82]\%). sIL-12p7 levels were significantly higher in patients with severely impaired FMD (FMD $<4.00, \mathrm{n}=$ $17)$, compared with normal or moderately impaired FMD (FMD $>=4, \mathrm{n}=21$ ): 10.70 [10.72] versus 4.33 [7.81] pg/ $\mathrm{ml}(\mathrm{p}=0.002)$ (Fig. 1). FMD correlated significantly with serum concentrations of sIL-12p7 ( $\mathrm{p}=0.024, \mathrm{r}=-0.365)$, but not with sIL-4 ( $\mathrm{p}=0.360, \mathrm{r}=0.153), \operatorname{IFN}-\mathrm{g}(\mathrm{p}=0.275$, $\mathrm{r}=-0.182)$, IFN-b $(\mathrm{p}=0.498, \mathrm{r}=-0.113)$, IFN-a $(\mathrm{p}=0.594$, $\mathrm{r}=-0.089)$ and TNFa $(\mathrm{p}=0.167, \mathrm{r}=-0.229)$ (Fig. 2). FMD correlated significantly with myocardial CD3+ leukocytes $(\mathrm{p}=0.015, \mathrm{r}=-0.398)$ and CD4+ leukocytes $(\mathrm{p}=0.023, \mathrm{r}$ $=-0.374)$. 


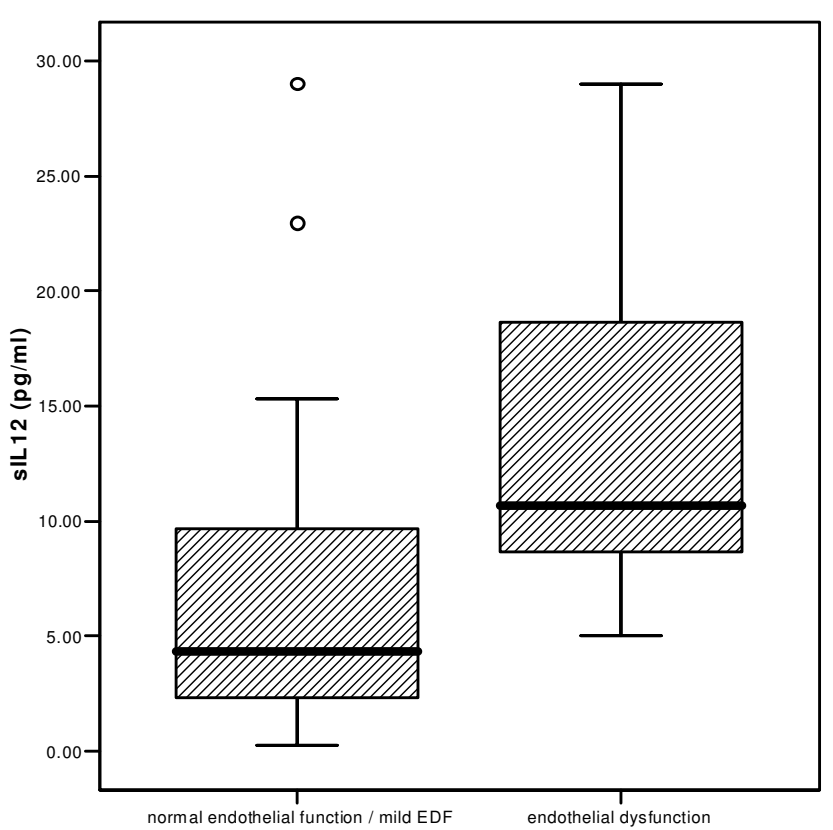

Figure I

slL-I 2p7 concentrations for patients with severely impaired endothelial function (FMD < 4.00, $n=17$ ), compared with normal or moderately impaired endothelial function (FMD $>=4, n=2 I)(p=0.002)$.

In the patient subgroup with myocardial inflammation, similar correlations were observed as for the total study population, additionally however, we found a significant correlation between FMD and TNFa ( $p=0.017, r=0.432)$.

\section{Endothelium independent vasodilation}

Endothelium independent vasodilation in response to GTN was not significantly impaired in the study population (GTN-MD 23.67 [8.21]\%). No significant correlations were observed between GTN-MD and sIL-4, IFN-g, IFN-b, IFN-a, sIL-12p7 and TNF-a. GTN-MD correlated significantly with myocardial CD3+ $(\mathrm{p}=0.024, \mathrm{r}=$ $0.370)$ and CD45RO leukocytes ( $\mathrm{p}=0.002, \mathrm{r}=-0.487)$.

\section{Impact of age and hemodynamic parameters}

Age, ejection fraction and other hemodynamic measurements did not vary extensively among the study population, therefor, therse parameters had no significant impact on endothelial function or cytokine concentration or endothelial activation, with the exception of a correlation between PCWP and IFNg ( $\mathrm{p}=0.001, \mathrm{r}=0.571)$.

\section{Discussion}

Endothelial dysfunction of peripheral arteries has been associated with myocardial inflammation and myocardial virus persistence, even in the absence of severely impaired left ventricular function [1-3]. The link between peripheral endothelial dysfunction and non-ischemic myocardial disease has remained obscure until now. In this study, we have demonstrated for the first time a relationship between circulating cytokines and peripheral endothelial dysfunction in patients with non-ischemic myocardial disease with preserved or only mildly impaired left ventricular function. Generalized inflammatory immune responses are known to be associated with peripheral endothelial dysfunction [4-8]. In this study, we focused on patients with chronic myocardial disease, so far thought off to be localized, where significant acute systemic inflammation or acute myocarditis was excluded.

We found, that endothelial dysfunction of peripheral arteries in patients with non-ischemic heart disease is associated with elevated sIL-12p7 concentrations in venous serum. sIL-12p7 activates NK-cells and displays proinflammatory actions which may potentially result in endothelial dysfunction. For sIL-4, IFN-g, IFN-b and IFNa no association with endothelial dysfunction was observed. For s-IL-4 this was expected, as it inhibits cytokine and protease production and therefor may protect endothelium. IFN-g can display proinflammatory as well as antiinflammatory properties, which may explain, that a correlation with endothelial function was observed for sIL-12p7 but not for IFN-g.

In patients with myocardial inflammation, there was also a significant correlation between TNFa and endothelial function, impaired FMD is associated with lower TNFa concentrations. TNFa activates macrophages, induces expression of cellular adhesion molecules, and enhances prostaglandine and metalloproteinase production. It is elevated in patients with heart failure [20,21], but studies with the intention to block its actions have not conclusively shown prognostic benefits. In our study population with only mild or regional LV-dysfunction, TNFa levels were not markedly elevated. Reduced TNFa concentrations in the presence of myocardial inflammation may reflect an impaired ability to induce an adequate immune response, with damage of the endothelium by the inflammation inducing agent.

The association between endothelial function and circulating cytokines in patients with non-ischemic cardiomyopathy helps to understand pathomechanisms in myocardial disease and may explain symptoms. Whether cytokine production is localized to areas of inflammation or virus persistence in the heart or if it is due to generalized vascular inflammation cannot be differentiated by this study. Endothelial dysfunction may be induced by circulating cytokines through decreased production or decreased bioavailability of endothelium derived nitric oxide. 

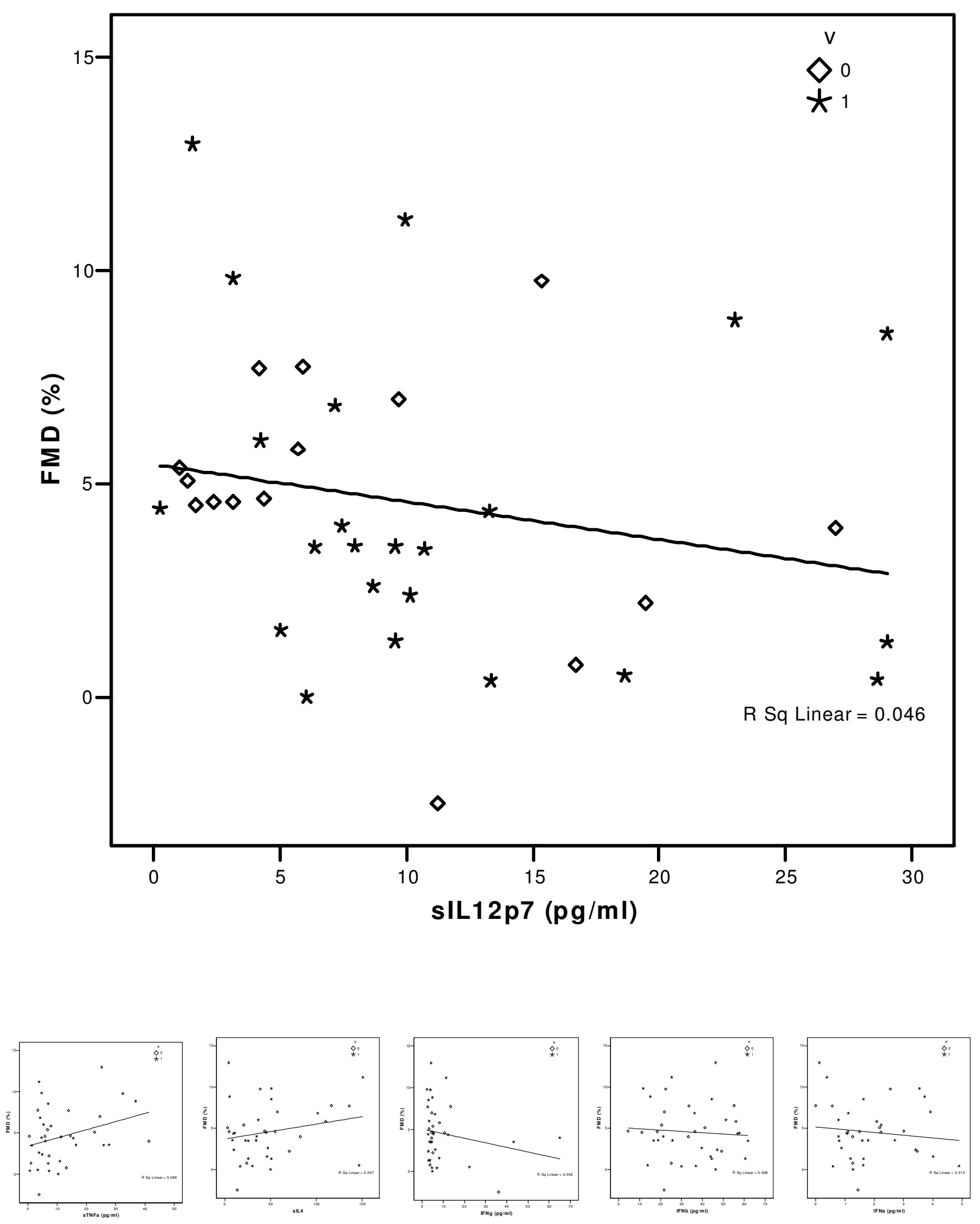

Figure 2

Endothelial function (FMD) of peripheral arteries in relation to circulating cytokine concentrations: sILI2 (top), TNF-a, sIL4, IFNg, IFNb and IFNa (bottom). Significant correlation for FMD and sILI 2 ( $p=0.024$ ), but not for other cytokines. 


\section{Conclusion}

Elevated cytokine sIL-12p7 concentrations in the peripheral circulation in patients with non-ischemic heart disease are associated with systemic endothelial dysfunction. These circulating cytokines may explain, that in patients with non-ischemic heart disease endothelial dysfunction is not restricted to the coronary circulation, but also involves systemic arteries. This finding is clinically important, as endothelial function represents an important predictor of prognosis [9-12] and may influence therapeutic decisions.

\section{Conflict of interests}

The author(s) declare that they have no competing interests.

\section{References}

I. Vallbracht KB, Schwimmbeck PL, Kühl U, Rauch U, Seeberg B, Schultheiss HP: Differential aspects of endothelial function of the coronary microcirculation considering myocardial virus persistence, endothelial activation, and myocardial leukocyte infiltrates. Circulation 2005, I I I: |784-|79|

2. Vallbracht KB, Schwimmbeck PL, Seeberg B, Kuhl U, Schultheiss HP Endothelial Dysfunction of Peripheral Arteries in Patients with Immunohistologically Confirmed Myocardial Inflammation Correlates with Endothelial Expression of Human Leukocyte Antigens and Adhesion Molecules in Myocardial Biopsies. J Am Coll Cardiol 2002, 40:5I5-520.

3. Vallbracht KB, Schwimmbeck PL, Kühl U, Seeberg B, Schultheiss HP. Endothelium dependent flow-mediated vasodilation of systemic arteries is impaired in patients with myocardial virus persistence. Circulation 2004, I 10:2938-2945.

4. Hingorani AD, Cross J, Kharbanda RK, Mullen MJ, Bhagat K, Taylor M, Donald AE, Palacios M, Griffin GE, Deanfield JE, MacAllister RJ, Vallance P: Acute Systemic Inflammation Impairs EndotheliumDependent Dilatation in Humans. Circulation 2000, 1 02:994-999.

5. Dhillon R, Clarkson P, Donald AE, Powe AJ, Nash M, Novelli V, Dillon MJ, Deanfield JE: Endothelial dysfunction late after Kawasaki disease. Circulation 1996, 94:2103-2106.

6. Raza K, Thambyrajah J, Townend JN, Exley AR, Hortas C, Filer A, Carruthers DM, Bacon PA: Suppression of Inflammation in Primary Systemic Vasculitis Resores Vascular Endothelial Function: Lessons for Atherosclerotic Disease? Circulation 2000, 102: 1470-1472.

7. Fichtescherer S, Rosenberger G, Walter DH, Breuer S, Dimmeler S, Zeiher AM: Elevated C-Reactive Protein Levels and Impaired Endothelial Vasoreactivity in Patients with Coronary Artery Disease. Circulation 2000, 102:1000-1006.

8. Vita JA, Keaney JF Jr, Larson MG, Keyes MJ, Massaro JM, Lipinska I, Lehmann BT, Fan S, Osypiuk E, Wilson PWF, Vasan RS, Mitchell GF, Benjamin EJ: Brachial artery vasodilator function and systemic inflammation in the Framingham Offspring Study. Circulation 2004, I 1 0:3604-3609.

9. Schächinger V, Britten MB, Zeiher AM: Prognostic Impact of Coronary Vasodilator Dysfunction on Adverse Long-Term Outcome of Coronary Heart Disease. Circulation 2000, I01:1899-1906.

10. Suwaidi JA, Hamasaki S, Higano ST, Nishimura RA, Holmes DR Jr, Lerman A: Long-Term Follow-Up of Patients With Mild Coronary Artery Disease and Endothelial Dysfunction. Circulation 2000, 101:948-954.

II. Halcox JP, Schenke WH, Zalos G, Mincemoyer R, Prasad A, Waclawiw MA, Nour KR, Quyyumi AA: Prognostic value of coronary vascular endothelial function. Circulation 2002, 106:653-658.

12. Davis SF, Yeung AC, Meredith IT, Charbonneau F, Ganz P, Selwyn AP, Anderson TJ: Early endothelial dysfunction predicts the development of transplant coronary artery disease at I year posttransplant. Circulation 1996, 93:457-462.
13. Ridker PM, Cushman M, Stampfer MJ, Tracy RP, Hennekens $\mathrm{CH}$ : Inflammation, aspirin and the risk of cardiovascular disease in apparently healthy men. N Engl J Med I 997, 336( I 4):973-979.

14. Ridker PM, Buring JE, Shih J, Matias M, Hennekens $\mathrm{CH}$ : Prospective study of C-reactive protein and the risk of future cardiovascular events among apparently healthy women. Circulation 1998, 98(8):731-733.

15. Tsutamoto T, Hisanaga T, Wada A, Maeda K, Ohnishi M, Fukai D, Mabuchi N, Sawaki M, Kinoshita M: Interleukin-6 spillover in the peripheral circulation increases with the severity of heart failure, and the high plasma level of interleukin-6 is an important prognostic predictor in patients with congestive heart failure. J Am Coll Cardiol I998, 31:39I-398.

16. Kubo SH, Rector TS, Bank AJ, Williams RE, Heifetz SM: Endothelium-dependent vasodilation is attenuated in patients with heart failure. Circulation 1991, 84:1589-1596.

17. Drexler H, Hayoz D, Münzel T, Horning B, Just H, Brunner HR, Zelis R: Endothelial function in chronic congestive heart failure. Am J Cardiol 1992, 69:1596-160I.

18. Zelis R, Hayoz D, Drexler H, Münzel T, Horning B, Zeiher AM, Just $H$, Brunner HR: Arterial dilatory reserve in congestive heart failure. J Hypertens Suppl 1992, I0(6):S65-67.

19. Hornig B, Arakawa N, Haussmann D, Drexler H: Differential effects of quinaprilat on endothelial function of conduit arteries in patients with chronic heart failure. Circulation 1998 , 98:2842-2848.

20. Torre-Amione G, Kapadia S, Benedict C, Oral H, Young JB, Mann DL: Proinflammatory cytokine levels in patients with depressed left ventricular ejection fraction: a report from the Studies of left ventricular dysfunction (SOLVD). J Am Coll Cardiol 1996, 27: $120|-| 206$.

2I. Deswal A, Peterson NJ, Feldman AM, Young JB, White BG, Mann DL: Cytokines and cytokine receptors in advanced heart failure: an analysis of the cytokine database from the Vesnarinone Trial (VEST). Circulation 200I, 103:2055-2059.

22. Celermajer DS, Sorensen KE, Bull C, Robinson J, Deanfield JE: Endothelium-dependent dilation in the systemic arteries of asymptomatic subjects relates to coronary risk-factors and their interaction. J Am Coll Cardiol 1994, 24: I468-I 474.

23. Reddy KG, Nair RN, Sheehan HM, Hodgson JM: Evidence that selective endothelial dysfunction may occur in the absence of angiographic or ultrasound atherosclerosis in patients with risk-factors for atherosclerosis. J Am Coll Cardiol 1994, 23:833-843

24. Celermajer DS, Sorensen KE, Georgakopoulos D, Bull C, Thomas O, Robinson J, Deanfield JE: Cigarette smoking is associated with dose-related and potentially reversible impairment of endothelium-dependent dilation in healthy young adults. Circulation 1993, 88(part I):2149-2I55.

25. Gokce N, Holbrook M, Hunter LM, Palmisano J, Vigalok E, Keaney JF Jr, Vita JA: Acute Effects of Vasoactive Drug Treatment on Brachial Artery Reactivity. J Am Coll Cardiol 2002, 40:76I-765.

26. Celermajer DS, Sorensen KE, Gooch VM, Spiegelhalter DJ, Miller OI, Sullivan ID, Lloyd JK, Deanfield JE: Non-invasive detection of endothelial dysfunction in children and adults at risk of atherosclerosis. Lancet 1992, 340: IIII-IIII.

27. Sorensen KE, Celermajer DS, Spiegelhalter DJ, Georgakopoulos D, Robinson J, Thomas $O$, Deanfield J: Non-invasive measurement of human endothelium dependent arterial responses: accuracy and reproducibility. Br Heart J 1995, 74:247-253.

28. Corretti MC, Anderson T], Benjamin E), Celermajer D, Charbonneau F, Creager MA, Deanfield J, Drexler H, Gerhard-Herman M, Herrington D, Vallance P, Vita J, Vogel R: Guidelines for the ultrasound assessment of flow mediated vasodilation of the brachial artery: a report of the International Brachial Artery Reactivity Task Force. J Am Coll Cardiol 2002, 39:257-265.

29. Kühl U, Noutsias M, Seeberg B, Schultheiss HP: Immunohistological evidence for a chronic intramyocardial inflammatory process in dilated cardiomyopathy. Heart 1996, 75(3):295-300.

30. Noutsias M, Seeberg B, Schultheiss HP, Kuhl U: Expression of Cell Adhesion Molecules in Dilated Cardiomyopathy. Circulation 1999, 99:2|24-2|3|. 